\title{
Triptorelin stimulated luteinizing hormone concentrations for diagnosing central precocious puberty: study of diagnostic accuracy
}

\author{
Rade Vukovic (i) ${ }^{1,2} \cdot$ Tatjana Milenkovic $^{1} \cdot$ Ivan Soldatovic ${ }^{2} \cdot$ Sandra Pekic ${ }^{2,3} \cdot$ Katarina Mitrovic $^{1,2} \cdot$ \\ Sladjana Todorovic ${ }^{1}$
}

Received: 23 July 2021 / Accepted: 13 November 2021 / Published online: 26 November 2021

(C) The Author(s), under exclusive licence to Springer Science+Business Media, LLC, part of Springer Nature 2021

\begin{abstract}
Purpose Gonadotropin-releasing hormone $(\mathrm{GnRH})$ stimulation test is the gold standard for diagnosing central precocious puberty (CPP). However, intravenous GnRH is not always readily available. The aim of the present study was to evaluate the diagnostic accuracy of triptorelin-stimulated luteinizing hormone (LH) concentrations in the diagnosis of CPP among girls presenting with premature thelarche compared to the gold standard GnRH test.

Methods A prospective, case-control (CPP vs isolated premature thelarche), clinical study evaluating the diagnostic accuracy of triptorelin-stimulated LH concentrations in 60 girls with premature thelarche was performed. All girls underwent stimulation with subcutaneous triptorelin injection and intravenous $\mathrm{GnRH}$ in a randomized order. During the stimulation test with triptorelin, LH and FSH were measured at time 0, 30, 60, 90, 120, and $180 \mathrm{~min}$ after the injection. Estradiol was sampled $24 \mathrm{~h}$ after the injection. During the GnRH test, LH and FSH were measured at time 0, 30, 45, and 60 min. Girls with peak GnRH-stimulated LH concentrations $\geq 5.0 \mathrm{IU} / \mathrm{L}$ were classified as having CPP. Area under the curve (AUC) for triptorelin-stimulated LH concentrations was assessed using the receiver operating characteristic (ROC) analysis.

Results Triptorelin-stimulated LH concentrations were significantly higher in girls who had CPP according to the GnRH test (53.3\%). LH peaked at $180 \mathrm{~min}$ after the triptorelin injection. The highest diagnostic accuracy for CPP (AUC $=0.973$, sensitivity $96.9 \%$, specificity $89.3 \%$ ) at $180 \mathrm{~min}$ was at a $\mathrm{LH}$ concentration $\geq 3.4 \mathrm{IU} / \mathrm{L}$. The $24 \mathrm{~h}$ estradiol concentration did not improve the predictive model.

Conclusions Measuring LH concentrations $180 \mathrm{~min}$ after triptorelin injection with a cut-off value of $\geq 3.4 \mathrm{IU} / \mathrm{L}$ demonstrated a high diagnostic accuracy compared to the GnRH test. Thus, stimulation with triptorelin can be used as a reliable alternative for diagnosing CPP in girls with premature thelarche.
\end{abstract}

Keywords Premature thelarche $\cdot$ Central precocious puberty $\cdot \mathrm{GnRH} \cdot$ Triptorelin $\cdot$ Diagnostic accuracy study

\section{Introduction}

Early onset of breast development in girls younger than 8 years is increasingly common [1-3]. Many of these girls

Rade Vukovic

radevukovic9@gmail.com

1 Department of Endocrinology, Mother and Child Health Care Institute of Serbia "Dr Vukan Cupic", Radoja Dakica 8, 11070 Belgrade, Serbia

2 School of Medicine, University of Belgrade, Dr Subotica 8, 11000 Belgrade, Serbia

3 Neuroendocrinology Department, Clinic for Endocrinology, Diabetes and Metabolic Diseases, Clinical Centre of Serbia, Dr Subotica 13, 11000 Belgrade, Serbia have isolated premature thelarche (IPT) without actual hypothalamic-pituitary-gonadal (HPG) activation, and do not need any kind of therapeutic intervention [3, 4]. However, in $21-60 \%$ of cases, the underlying cause may be central precocious puberty (CPP), in which case treatment with gonadotropin-releasing hormone $(\mathrm{GnRH})$ analogs should be considered [3, 5-8].

The GnRH stimulation test continues to be the gold standard in detecting activation of the HPG axis and confirmation of CPP [9-13]. Ultrasensitive chemiluminescence assays are used in many centers to analyze $\mathrm{LH}$, and a peak GnRH-stimulated LH concentration $\geq 5.0 \mathrm{IU} / \mathrm{L}$ is commonly used to define HPG activation in girls with premature thelarche $[3,14,15]$. However, intravenous GnRH preparation is not always readily available, in contrast to $\mathrm{GnRH}$ analogs such as triptorelin [11, 12, 16-19]. Stimulation of the HPG 
axis with GnRH analogs has been proposed as an alternative to the gold standard GnRH test [3, 11, 12, 20]. Triptorelin has a longer half-life and stronger affinity for the GnRH receptor. Thus it may provide a more comprehensive evaluation of the HPG axis and at the same time be less invasive for patients compared to the intravenous GnRH test $[12,21]$.

To the best of our knowledge, only two studies so far have assessed the use of triptorelin-stimulated LH concentrations in diagnosing CPP [11, 12]. Stimulation with triptorelin was performed using different sampling protocols in these studies, and only one study used the GnRH test as reference [11, 12].

The aim of the present study was to evaluate the diagnostic accuracy of triptorelin-stimulated LH concentrations compared to the gold standard GnRH test in girls with CPP. We also aimed to determine the most accurate LH cut-off in girls with CPP after injection with triptorelin.

\section{Patients and methods}

A prospective, case-control study evaluating the diagnostic accuracy of triptorelin-stimulated LH concentrations in girls with premature thelarche was performed, following the Standards for Reporting Diagnostic Accuracy (STARD) recommendations [22]. Triptorelin-stimulated LH concentrations (index test) were compared to the reference standard GnRH test results. The study was conducted at the Department of Endocrinology at the Mother and Child Health Care Institute of Serbia "Dr Vukan Cupic" during the period of November 2017 to September 2020. All girls referred to our endocrinology clinic for evaluation of premature thelarche during the study period were considered for enrollment in the study. The study protocol was formally approved by the Hospital Ethics Committee and in accordance with the Declaration of Helsinki. Informed consents were obtained from parents or guardians of all participants, and all girls aged $>7$ years also personally assented to participate. Other inclusion criteria were: (1) premature thelarche defined by the onset of breast development prior to the age of 8 years, and (2) age 5-9 years at the time of testing. Clinical or laboratory findings suggestive of GnRHindependent precocious puberty, other endocrine (including thyroid function), systemic, or chronic illnesses, as well as use of medications known to alter the HPG axis, such as GnRH analogs, were considered as exclusion criteria.

Height and body mass index (BMI) percentiles and standard deviation scores (SDS) were calculated according to WHO AnthroPlus software [23, 24]. Pubertal development was assessed according to Tanner stages [25]. The Greulich \& Pyle method was used for evaluation of bone ages [26]. Abdominal and pelvic ultrasound examinations were performed in all patients.
The sequence of the two tests was randomized with an interval of 15-20 days between them, due to the possibility of triptorelin inducing a long-lasting effect on the hormonal concentrations in the group who had GnRH stimulation after triptorelin. Randomization was performed using $\mathrm{R}$ 4.02 statistical software with randomizeR package, using an allocation ratio 1 and complete randomization algorithm. All tests were performed after an overnight fast between 0800 and 0900 hours in the morning.

Stimulation test with triptorelin (index test): an intravenous cannula was inserted into the right forearm and blood samples were drawn at time $0 \mathrm{~min}$ for $\mathrm{LH}$, folliclestimulating hormone (FSH), and estradiol, immediately before $100 \mu \mathrm{g} / \mathrm{m}^{2}$ (max. $100 \mu \mathrm{g}$ ) of $\mathrm{GnRH}$ analog (triptorelin; $0.1 \mathrm{mg} / \mathrm{mL}$ aqueous solution, Diphereline ; Ipsen Pharma Biotech, France, Paris) was administered as subcutaneous injection into the left deltoid region. Blood samples for LH and FSH were then collected at 30, 60, 90, 120 , and $180 \mathrm{~min}$ after the injection. The highest measured LH concentration during the test was considered to be the peak LH concentration. After $24 \mathrm{~h}$, another blood sample was drawn for LH, FSH and estradiol.

GnRH test (reference standard test): an intravenous cannula was inserted into the right forearm and blood samples were drawn at time $0 \mathrm{~min}$ for $\mathrm{LH}, \mathrm{FSH}$, and estradiol, immediately before $100 \mu \mathrm{g} / \mathrm{m}^{2}$ (max. $100 \mu \mathrm{g}$ ) dose of GnRH (gonadorelin; $0.1 \mathrm{mg} / \mathrm{mL}$, Relefact LH-RH ${ }^{\oplus}$; Sanofi-Aventis, Germany, Frankfurt am Main) was administered as an intravenous bolus. Blood samples for LH and FSH were then collected at 30, 45 and $60 \mathrm{~min}$ after the injection.

Girls with peak GnRH-stimulated LH concentrations $\geq 5.0 \mathrm{IU} / \mathrm{L}$ were classified as having central precocious puberty (CPP group-cases) [3, 14, 15]. All girls were followed-up for a minimum of 9 months. Girls with advancement of pubertal signs, bone age, or growth velocity during follow-up underwent a repeated GnRH test. All girls with CPP were referred for brain MRI in order to exclude an intracranial pathology.

Serum LH, FSH, and estradiol concentrations during both tests were measured using ultrasensitive chemiluminescence immunoassays (Abbott Architect plus i2000SR; Abbott Diagnostics, Abbott Park, IL, USA) with the lower limit of detection of $0.1 \mathrm{IU} / \mathrm{L}$ for $\mathrm{LH}$ and FSH and $37 \mathrm{pmol} /$ $\mathrm{L}$ for estradiol. The intra- and interassay coefficients of variation were $\leq 1.3 \%$ and $\leq 2.5 \%$ for $\mathrm{LH}$ and $\leq 3.2 \%$ and $\leq 3.5 \%$ for FSH, respectively.

\section{Statistical analyses}

All statistical analyses were performed using IBM SPSS Statistics for Windows, version 20 (IBM Corp., Armonk, NY, USA) statistical package and R Statistical Software version 4.0.2 ( $\mathrm{R}$ Foundation for Statistical Computing, 
Vienna, Austria). Results were presented as numbers (\%), mean \pm standard deviation (SD), or median (25th-75th percentile), depending on data type and distribution. The differences in the means of variables between groups were tested using the parametric $t$-test or Mann-Whitney $U$ test accordingly. Categorical variables were tested using Pearson's chi-square test and chi-square test for trend. Pearson correlation was used to assess correlation between variables. Binary logistic regression was performed in order to assess the relationship between dependent variable (CPP vs IPT) and independent variables (LH and estradiol concentrations after stimulation with triptorelin). Receiver operating characteristic (ROC) analysis was performed to determine the area under the curve (AUC) in order to evaluate the discriminative abilities of triptorelin-stimulated LH and estradiol concentrations at different sampling times. ROC analysis was performed for $\mathrm{LH}$ concentrations at all specific sampling times $(0,30,60,90,120$, and $180 \mathrm{~min})$ and for estradiol concentrations at $24 \mathrm{~h}$ after stimulation with triptorelin. ROC analysis was also performed for all peak $\mathrm{LH}$ concentrations irrespective of sampling times after stimulation with triptorelin. AUC was calculated from ROC analysis for all these variables in order to identify a classifier with the highest discriminative power (CPP vs IPT). After identifying sampling time with the highest AUC, optimal cut-off value of triptorelin-stimulated LH concentrations for discriminating CPP and IPT was established by determining the highest diagnostic performance based on best sensitivity and specificity ratio on the ROC curve. Diagnostic accuracy was the percentage of true findings (sum of girls with CPP and triptorelin-stimulated LH concentrations above the cut-off point and girls with IPT and LH concentrations below the cut-off, divided by the number of total girls). All probability values less than 0.05 were considered significant.

\section{Results}

Sixty girls with premature thelarche were included in the study. Median age at the onset of thelarche was 6.9 years, with interquartile range (IQR) of 5.9-7.7 years. At the time of testing, the majority of girls had breast development at Tanner stage $2(63 \%, n=38), 28 \%(n=17)$ were at Tanner stage 3 and $9 \%(n=5)$ were at stage Tanner stage 4 . A detailed overview of clinical characteristics of all

Table 1 Clinical characteristics of girls in CPP and IPT groups (classified by the initial GnRH test findings)

\begin{tabular}{|c|c|c|c|}
\hline & $\begin{array}{l}\text { CPP } \\
(n=32)\end{array}$ & $\begin{array}{l}\text { IPT } \\
(n=28)\end{array}$ & $P$ value \\
\hline Age (years) & $8.5(7.9-8.9)$ & $7.4(7.0-8.1)$ & $0.001 * *$ \\
\hline Age at onset of thelarche (years) & $7.3(6.7-7.9)$ & $6.5(5.0-7.0)$ & $0.002^{* *}$ \\
\hline Breast development stage & & & $0.003^{* *}$ \\
\hline Tanner stage 2 & $15(46.9 \%)$ & $23(82.1 \%)$ & \\
\hline Tanner stage 3 & $12(37.5 \%)$ & $5(17.9 \%)$ & \\
\hline Tanner stage 4 & $5(15.6 \%)$ & $0(0 \%)$ & \\
\hline Pubic hair development stage & & & $0.023^{*}$ \\
\hline Tanner stage 1 & $14(43.8 \%)$ & $20(71.4 \%)$ & \\
\hline Tanner stage 2 & $9(28.1 \%)$ & $7(25.0 \%)$ & \\
\hline Tanner stage 3 & $8(25.0 \%)$ & $0(0 \%)$ & \\
\hline Tanner stage 4 & $1(3.1 \%)$ & $1(3.6 \%)$ & \\
\hline Height (SDS) & $1.46(0.82-2.35)$ & $1.11(0.52-1.88)$ & 0.529 \\
\hline MPH (SDS) & $0.43(-0.13-0.86)$ & $0.46(0.20-0.92)$ & 0.387 \\
\hline Height (SDS)-MPH (SDS) & $1.20(0.58-1.65)$ & $0.76(0.31-1.29)$ & 0.194 \\
\hline BMI (SDS) & $0.51(-0.28-1.25)$ & $1.06(0.36-1.67)$ & $0.031 *$ \\
\hline Bone age (years) & $10.5(8.9-11.2)$ & $8.3(7.0-10.6)$ & $0.010^{*}$ \\
\hline Bone age (years)-age (years) & $1.88(0.99-2.62)$ & $0.87(0.18-2.17)$ & 0.123 \\
\hline Uterine length $(\mathrm{mm})$ & $39.3 \pm 8.5$ & $34.1 \pm 5.4$ & $0.010^{*}$ \\
\hline Max. ovarian volume (mL) & $2.14 \pm 0.89$ & $1.98 \pm 0.92$ & 0.454 \\
\hline Follow-up length (months) & $22.6(18.9-29.7)$ & $20.9(11.7-30.1)$ & 0.227 \\
\hline
\end{tabular}

$C P P$ central precocious puberty, $I P T$ isolated premature thelarche, GnRH gonadotropin-releasing hormone, $S D S$ standard deviation score, $M P H$ midparental height, $B M I$ body mass index. Results are presented as absolute numbers $(\%)$, means \pm standard deviation (SD), or median (25th-75th percentile). Statistically significant differences are marked with * for $p<0.05$ and $* *$ for $p<0.01$. 
Table 2 Laboratory characteristics of girls in CPP and IPT groups (classified by the initial GnRH test findings)

\begin{tabular}{|c|c|c|c|}
\hline & $\begin{array}{l}\text { CPP } \\
(n=32)\end{array}$ & $\begin{array}{l}\text { IPT } \\
(n=28)\end{array}$ & $P$ value \\
\hline \multicolumn{4}{|l|}{ GnRH test } \\
\hline Basal FSH ${ }^{\mathrm{b}}$ (IU/L) & $4.3(2.8-5.1)$ & $1.5(0.6-1.8)$ & $<0.001 * *$ \\
\hline Peak FSH (IU/L) & $10.7(8.6-11.2)$ & $8.6(5.7-11.7)$ & $0.025^{*}$ \\
\hline Basal $\mathrm{LH}^{\mathrm{c}}(\mathrm{IU} / \mathrm{L})$ & $1.3(0.7-2.3)$ & $0.1(0.1-0.1)$ & $<0.001 * *$ \\
\hline Peak LH (IU/L) & $10.3(7.5-17.9)$ & $2.5(2.2-3.2)$ & \\
\hline Basal estradiol (pmol/L) & $102(37-152)$ & $37(37-37)$ & $<0.001 * *$ \\
\hline \multicolumn{4}{|l|}{ Triptorelin test } \\
\hline Basal FSH (IU/L) & $4.4(3.0-5.7)$ & $1.4(0.5-1.9)$ & $<0.001 * *$ \\
\hline Peak FSH (IU/L) & $17.1(14.0-19.9)$ & $13.3(8.8-17.4)$ & $0.006 * *$ \\
\hline Basal LH (IU/L) & $1.7(0.6-2.7)$ & $0.1(0.1-0.1)$ & $<0.001 * *$ \\
\hline 30 min LH (IU/L) & $10.3(4.9-19.8)$ & $1.4(0.8-2.2)$ & $<0.001 * *$ \\
\hline $60 \mathrm{~min} \mathrm{LH}(\mathrm{IU} / \mathrm{L})$ & $12.4(6.1-19.7)$ & $1.7(0.9-2.3)$ & $<0.001 * *$ \\
\hline $90 \min \mathrm{LH}(\mathrm{IU} / \mathrm{L})$ & $12.9(6.7-18.4)$ & $1.8(1.0-2.6)$ & $<0.001 * *$ \\
\hline $120 \min \mathrm{LH}(\mathrm{IU} / \mathrm{L})$ & $12.7(8.0-18.1)$ & $2.0(1.1-2.7)$ & $<0.001 * *$ \\
\hline $180 \min \mathrm{LH}(\mathrm{IU} / \mathrm{L})$ & $15.8(11.0-24.6)$ & $2.1(1.2-2.7)$ & $<0.001 * *$ \\
\hline 24 h LH (IU/L) & $8.8(3.7-13.8)$ & $0.8(0.6-1.2)$ & $<0.001 * *$ \\
\hline Peak LH (IU/L) & $18.5(12.9-24.6)$ & $2.1(1.3-3.0)$ & $<0.001 * *$ \\
\hline Basal estradiol (pmol/L) & $66(37-163)$ & $37(37-37)$ & $<0.001 * *$ \\
\hline $24 \mathrm{~h}$ estradiol $(\mathrm{pmol} / \mathrm{L})$ & 735 (396-1041) & $157(56-378)$ & $<0.001 * *$ \\
\hline
\end{tabular}

$C P P$ central precocious puberty, IPT isolated premature thelarche, GnRH gonadotropin-releasing hormone, FSH follicle-stimulating hormone, $L H$ luteinizing hormone. Results are presented as median (25th-75th percentile); statistically significant differences are marked with $*$ for $p<0.05$ and $* *$ for $p<0.01$

participants is presented in Table 1. There were no statistically significant differences in the laboratory findings, including LH and estradiol concentrations, between the girls randomized for the GnRH test $(n=30)$ and girls randomized for the stimulation with triptorelin as the first test.

Peak GnRH-stimulated LH concentrations $\geq 5.0 \mathrm{IU} / \mathrm{L}$ were detected in $53.3 \%(n=32)$ girls, classifying them in the CPP group (Table 2). During the first 6 months of follow-up, six girls who were initially classified as IPT showed signs of pubertal progression and had pubertal peak LH concentrations on repeat $\mathrm{GnRH}$ testing. The median age of these girls was 8.2 years (IQR 7.6-8.8 years). These girls were allocated into the IPT group according to the initial test results.

The GnRH test produced higher LH concentrations in the CPP group (Table 2). Peak LH concentrations occurred after $30 \mathrm{~min}$ in $61.7 \%(n=37)$ of patients, after $45 \mathrm{~min}$ in $33.3 \%(n=20)$, and after $60 \mathrm{~min}$ in $5.0 \%(n=3)$ after stimulation with GnRH. Stimulation with triptorelin produced significantly higher LH concentrations in the CPP group during all sampling times and peaked at $180 \mathrm{~min}$ in both groups (Fig. 1). In girls with CPP stimulated with triptorelin, LH peaked at $30 \mathrm{~min}$ in $12.5 \%(n=4)$ girls, at $60 \mathrm{~min}$ in $21.9 \%(n=7)$, at $90 \mathrm{~min}$ in $3.1 \%(n=1)$, and at $180 \mathrm{~min}$ in $62.5 \%(n=20)$. All girls with LH peak at 30, 60 , and $90 \mathrm{~min}$ also had high LH concentrations at $180 \mathrm{~min}$ (11.0-32.2 IU/L). As shown in Table 2, concentrations of estradiol after stimulation with triptorelin were also higher in the CPP group, with a median stimulated estradiol concentration of $735 \mathrm{pmol} / \mathrm{L}$ in the $\mathrm{CPP}$ group compared to $157 \mathrm{pmol} / \mathrm{L}$ in the IPT group.

Peak LH concentrations measured after stimulation with triptorelin showed a significant correlation with peak GnRH-stimulated LH concentrations using log-transformed values, with Pearson correlation coefficient $r=0.825$ ( $p<$ 0.001), as shown in Fig. 2.

ROC analysis showed that LH concentrations $180 \mathrm{~min}$ after triptorelin injection had the highest diagnostic accuracy for diagnosing $\mathrm{CPP}$, with $\mathrm{AUC}=0.973$. Using peakstimulated LH concentrations after triptorelin injection did not improve diagnostic accuracy (AUC 0.968), and stimulated estradiol concentrations at $24 \mathrm{~h}$ had significantly lower $\mathrm{AUC}=0.891$.

LH concentrations $180 \mathrm{~min}$ after triptorelin injection showed the optimal sensitivity $(96.9 \%)$ and specificity $(89.3 \%)$ ratio for diagnosing CPP on the ROC curve, equivalent to a $\mathrm{LH}$ cut-off concentration of $\geq 3.4 \mathrm{IU} / \mathrm{L}$ (Fig. 3). This cut-off value correctly classified 25/28 IPT and $31 / 32$ CPP, with total diagnostic accuracy of $93.3 \%$. Positive predictive value (PPV) of stimulation with triptorelin was $91.2 \%$ and negative predictive value (NPV) $96.2 \%$.

Binary logistic regression was performed using CPP as outcome and concentrations of LH $180 \mathrm{~min}$ and estradiol $24 \mathrm{~h}$ after triptorelin injection as independent variables. In the first step with $180 \mathrm{~min} \mathrm{LH}$ as the only independent variable, AUC of the model was 0.973 . Including the $24 \mathrm{~h}$ estradiol concentration in the model resulted in no change at all to the AUC (AUC $=0.973$ ), suggesting that $24 \mathrm{~h}$ estradiol concentration does not improve the discriminative power of LH concentration 180 min after stimulation with triptorelin.

Besides from mild local pain at the time and site of injection, no adverse events from subcutaneous triptorelin and intravenous $\mathrm{GnRH}$ administration were noted in our patients.

\section{Discussion}

The present study identified a high diagnostic accuracy of LH concentrations after triptorelin injection when diagnosing CPP in girls with premature thelarche compared to the gold standard GnRH test. This suggests that triptorelinstimulated LH concentrations can be used as a reliable 
Fig. 1 Median LH

concentrations during the seven timepoints after triptorelin injection in CPP and IPT groups (classified by the GnRH test findings)

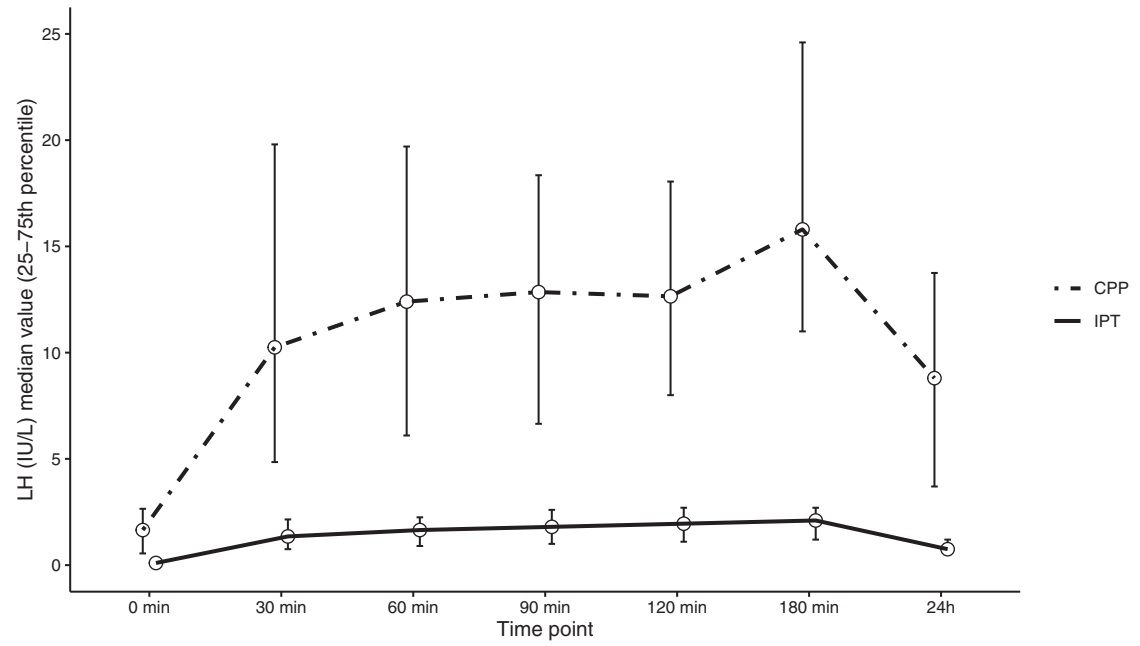

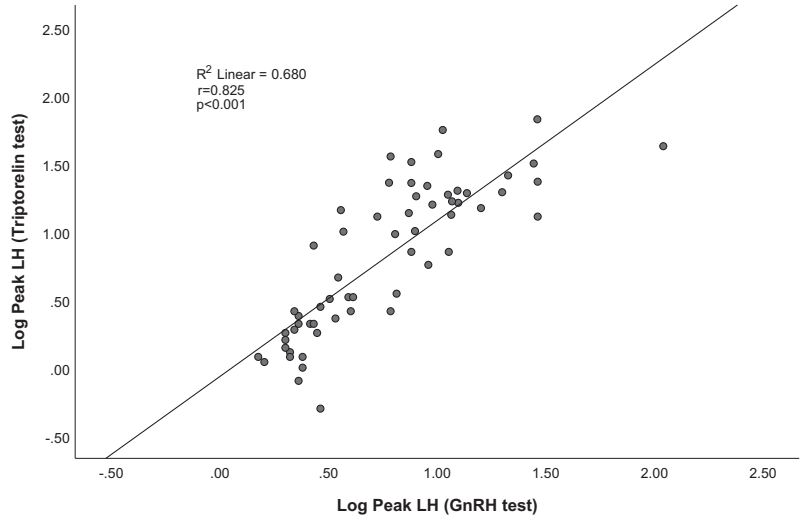

Fig. 2 Correlation between log-transformed peak luteinizing hormone (LH) concentrations after triptorelin injection with peak LH values during GnRH test

alternative for evaluation of the HPG axis when intravenous $\mathrm{GnRH}$ is unavailable.

Premature onset of breast development in girls younger than 8 years is increasingly common and frequently associated with childhood obesity [1-3]. To confirm (or exclude) CPP as the cause of premature thelarche, it is necessary to evaluate the pubertal activation of the HPG axis [3]. Although consistent with precocious puberty, clinical parameters such as accelerated height velocity, significant bone age advancement, uterine and ovarian enlargements should not be considered reliable in distinguishing IPT from CPP $[3,6,7,17]$. Accelerated height velocity and advanced bone age is also seen in girls who are overweight and particularly with concomitant adrenarche [27, 28]. In addition, bone age advancement and uterine/ovarian enlargements can be absent in some girls with premature thelarche due to CPP, resulting in missed or delayed diagnosis. Our study confirm this overlap of clinical characteristics between girls with CPP and IPT (Table 1), emphasizing the need for a laboratory examination of the HPG axis.

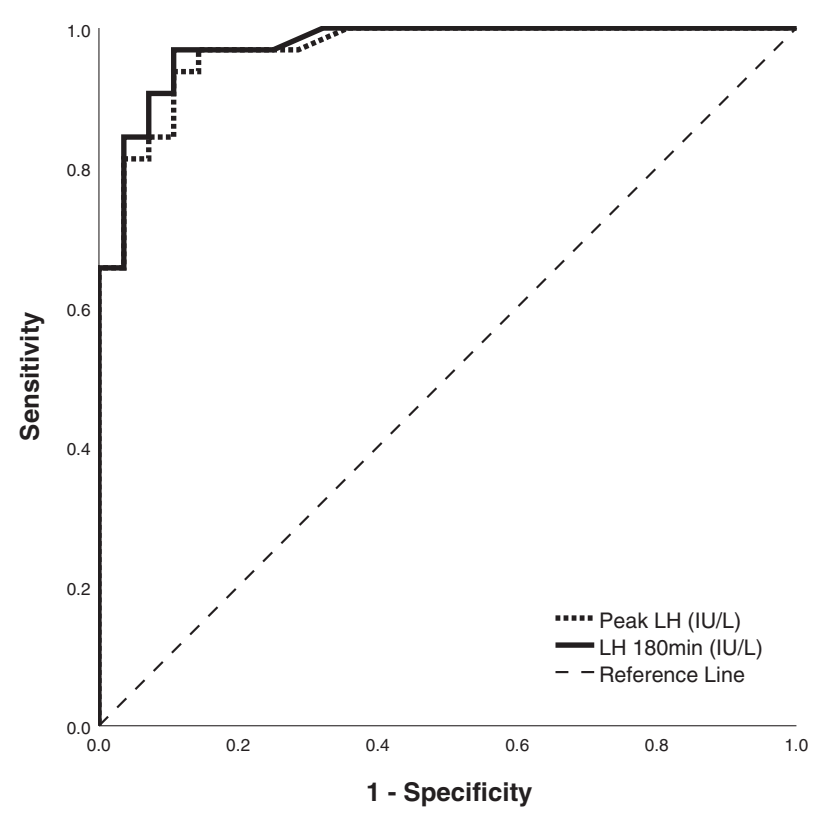

Fig. 3 Receiver operating characteristic (ROC) curve analysis of triptorelin-stimulated LH concentrations in diagnosing CPP as determined by the GnRH test findings. Solid line illustrates high AUC of 180 min LH concentration compared with the AUC when peak LH is used from all sampling times after triptorelin injection (dotted line)

The LH concentration is the most reliable diagnostic parameter, with random basal serum LH concentrations in the pubertal range confirming CPP. However, mildly elevated $\mathrm{LH}$ concentrations can be detected in prepubertal children, and recent findings indicate that pre-injection $\mathrm{LH}$ may even remain at pubertal concentrations during $\mathrm{GnRH}$ therapy in spite of lack of pubertal progression [3, 29, 30]. More importantly, basal LH concentrations below the pubertal range do not exclude CPP, emphasizing the need for evaluation of stimulated LH concentrations $[3,9,29,31,32]$. Thus, the GnRH stimulation test continues to be the gold standard for discriminating IPT vs CPP 
in girls with premature thelarche [9-13]. Due to frequent unavailability of intravenous GnRH in many countries, stimulation testing with a widely available $\mathrm{GnRH}$ analog such as triptorelin, shown to induce comparable peaks of LH secretion, has been proposed as an alternative test for diagnosing CPP [3, 11, 12, 16-20]. In the present study, the potency of triptorelin to stimulate $\mathrm{LH}$ secretion has been confirmed by a significant strong correlation of peak $\mathrm{LH}$ responses after triptorelin injection compared to peak GnRH-stimulated LH concentrations (Fig. 2).

Two previous studies have assessed the use of triptorelin in diagnosing CPP $[11,12]$. In the first study, Poomthavorn et al. measured LH concentrations at 0, 30, 60, 90, and 120 min after subcutaneous triptorelin injection in girls with CPP. The highest concentrations of LH were detected $60 \mathrm{~min}$ after injection of triptorelin. A sensitivity of $89.1 \%$ and a specificity of $91.3 \%$ was obtained for diagnosing CPP, equivalent to a triptorelin-stimulated peak LH cut-off concentration of $\geq 6 \mathrm{IU} / \mathrm{L}$. However, this study was retrospective and due to unavailability of intravenous $\mathrm{GnRH}$, the diagnosis of CPP was based on clinical criteria rather than on $\mathrm{GnRH}$ testing [11]. The second study, by Freire et al. [12], was a robustly designed prospective study of 46 girls with premature thelarche, using the GnRH test as reference standard. By combining $3 \mathrm{~h} \mathrm{LH}$ and $24 \mathrm{~h}$ estradiol cut-off concentrations after stimulation with triptorelin, Freire et al. obtained a high diagnostic accuracy of $96 \%$ (sensitivity $94 \%$, specificity $100 \%$ ). The protocol used different sampling times (before the triptorelin injection, after 3 and $24 \mathrm{~h}$ ), and LH was not measured at $60 \mathrm{~min}$, which has previously been associated with peak LH concentrations [11, 12]. In addition, the GnRH gold standard test was performed without measuring $\mathrm{LH}$ at 45 min, which has been shown to have the highest sensitivity in diagnosing CPP [12, 33, 34]. The protocol also required cumbersome blood sampling (estradiol) at $24 \mathrm{~h}$ after the triptorelin injection, resulting in significantly increased length of hospital stay and healthcare costs. Despite these variations, both studies clearly demonstrated the potency of triptorelin to cause an immediate rise in LH concentrations allowing clinicians to use it when evaluating girls for CPP.

In the present study, AUC analysis showed that LH concentrations $180 \mathrm{~min}$ after triptorelin injection had the highest diagnostic accuracy for diagnosing CPP. ROC curve analysis identified cut-off value for LH concentration $180 \mathrm{~min}$ after triptorelin injection of $\geq 3.4 \mathrm{IU} / \mathrm{L}$ as the optimal cut-off value, with high sensitivity $(96.9 \%)$, specificity (89.3\%), and diagnostic accuracy $(93.3 \%)$ for diagnosing CPP. Since sampling of $24 \mathrm{~h}$ estradiol did not improve the predictive model, according to this model inconveniently long hospital stays are unnecessary, benefitting patients and healthcare costs. Thus, we propose a one-blood-sample protocol for the assessment of triptorelin-stimulated $\mathrm{LH}$ response, by sampling $180 \mathrm{~min}$ after the administration of subcutaneous triptorelin injection. This strategy provides high diagnostic accuracy, short hospital stays, and is less invasive compared to the GnRH gold standard model and previously proposed test protocols using triptorelin.

Our study was limited by the fact that all girls were Caucasian and only included girls with premature thelarche who were otherwise healthy. In contrary, this is the first study to analyze all previously proposed blood-sampling times compared to the GnRH test findings.

As physicians and researchers, we strive for the best possible diagnostic and therapeutic modalities. However, we must always have in mind that not everyone in the world has access to the same level of medical care, including the medications available for both diagnostic and therapeutic purposes. That is exactly the case with the intravenous GnRH preparation that is often unavailable in countries such as India, Brazil, Thailand, or Serbia [11, 12, 16-19]. Also, with the widespread drug shortages seen during the current COVID-19 crisis and the global disruption of supply chains, the availability of the intravenous $\mathrm{GnRH}$ preparation may become affected even in wealthier countries worldwide $[35,36]$. In such settings, it is especially important to provide reliable alternative diagnostic methods, such as triptorelin, in order to provide the highest possible level of medical care for patients in regions where gold standard tests are not available.

In conclusion, measurement of $\mathrm{LH}$ concentrations at $180 \mathrm{~min}$ after subcutaneous injection of $100 \mu \mathrm{g}$ of triptorelin $(0.1 \mathrm{mg} / \mathrm{mL}$ aqueous solution), with a cut-off value of $\geq 3.4 \mathrm{IU} / \mathrm{L}$ demonstrated a high diagnostic accuracy of 93.3\% in diagnosing CPP. Thus, it can be used as a reliable alternative to the gold standard GnRH test when evaluating girls with premature thelarche for CPP.

\section{Data availability}

Original anonymized data can be made available upon request to the author.

Acknowledgements We gratefully acknowledge the participation of all patients and families, as well as the kind assistance of B. Opancina, laboratory staff, doctors, and nurses of Mother and Child Health Care Institute of Serbia "Dr. Vukan Cupic".

Author contributions R.V. designed the research study, gathered, and analyzed the data, and wrote the first draft of the manuscript. I.S. conducted statistical analyses. All authors contributed to study design, revised, read, and approved the final version of the manuscript.

\section{Compliance with ethical standards}

Conflict of interest The authors declare no competing interests. 
Ethical approval and consent to participate the study protocol was formally approved by the Hospital Ethics Committee and in accordance with the Declaration of Helsinki. Informed consents were obtained from the parents or guardians of all participants and assents from participants older than 7 years of age.

Publisher's note Springer Nature remains neutral with regard to jurisdictional claims in published maps and institutional affiliations.

\section{References}

1. L. Aksglaede, K. Sorensen, J.H. Petersen, N.E. Skakkebaek, A. Juul, Recent decline in age at breast development: the Copenhagen Puberty Study. Pediatrics. 123(5), e932-e939 (2009)

2. F.M. Biro, L.C. Greenspan, M.P. Galvez, S.M. Pinney, S. Teitelbaum, G.C. Windham et al. Onset of breast development in a longitudinal cohort. Pediatrics. 132(6), 1019-1027 (2013)

3. K. Bangalore Krishna, J.S. Fuqua, A.D. Rogol, K.O. Klein, J. Popovic, C.P. Houk et al. Use of gonadotropin-releasing hormone analogs in children: update by an international consortium. Horm. Res. Paediatr. 91(6), 357-372 (2019)

4. F.M. Biro, A. Pajak, M.S. Wolff, S.M. Pinney, G.C. Windham, M.P. Galvez et al. Age of menarche in a longitudinal US cohort. J. Pediatr. Adolesc. Gynecol. 31(4), 339-45 (2018)

5. S.Y. Zhu, M.L. Du, T.T. Huang, An analysis of predictive factors for the conversion from premature thelarche into complete central precocious puberty. J. Pediatr. Endocrinol. Metab. 21(6), 533-538 (2008)

6. J.S. Fuqua, Treatment and outcomes of precocious puberty: an update. J. Clin. Endocrinol. Metab. 98(6), 2198-2207 (2013)

7. T. Varimo, H. Huttunen, P.J. Miettinen, L. Kariola, J. Hietamaki, A. Tarkkanen et al. Precocious puberty or premature thelarche: analysis of a large patient series in a single tertiary center with special emphasis on 6- to 8-year-old girls. Front. Endocrinol. (Lausanne) 8, 213 (2017)

8. E.A. Eugster, Treatment of central precocious puberty. J. Endocr. Soc. 3(5), 965-972 (2019)

9. E.A. Resende, B.H. Lara, J.D. Reis, B.P. Ferreira, G.A. Pereira, M.F. Borges, Assessment of basal and gonadotropin-releasing hormone-stimulated gonadotropins by immunochemiluminometric and immunofluorometric assays in normal children. J. Clin. Endocrinol. Metab. 92(4), 1424-1429 (2007)

10. J.C. Carel, J. Leger, Clinical practice. Precocious puberty. N Engl J Med 358(22), 2366-2377 (2008)

11. P. Poomthavorn, P. Khlairit, P. Mahachoklertwattana, Subcutaneous gonadotropin-releasing hormone agonist (triptorelin) test for diagnosing precocious puberty. Horm. Res. 72(2), 114-119 (2009)

12. A.V. Freire, M.E. Escobar, M.G. Gryngarten, A.J. Arcari, M.G. Ballerini, I. Bergada et al. High diagnostic accuracy of subcutaneous Triptorelin test compared with GnRH test for diagnosing central precocious puberty in girls. Clin. Endocrinol. (Oxf) 78(3), 398-404 (2013)

13. L. Soriano-Guillen, J. Argente, Central precocious puberty, functional and tumor-related. Best. Pract. Res. Clin. Endocrinol. Metab. 33(3), 101262 (2019)

14. E.K. Neely, R.L. Hintz, D.M. Wilson, P.A. Lee, T. Gautier, J. Argente et al. Normal ranges for immunochemiluminometric gonadotropin assays. J. Pediatr. 127(1), 40-46 (1995)

15. Y. Pasternak, M. Friger, N. Loewenthal, A. Haim, E. Hershkovitz, The utility of basal serum LH in prediction of central precocious puberty in girls. Eur. J. Endocrinol. 166(2), 295-299 (2012)
16. M. Kumar, S. Mukhopadhyay, D. Dutta, Challenges and controversies in diagnosis and management of gonadotropin dependent precocious puberty: an Indian perspective. Indian J. Endocrinol. Metab. 19(2), 228-235 (2015)

17. V.N. Brito, A.M. Spinola-Castro, C. Kochi, C. Kopacek, P.C. Silva, G. Guerra-Junior, Central precocious puberty: revisiting the diagnosis and therapeutic management. Arch. Endocrinol. Metab. 60(2), 163-172 (2016)

18. L.G.A. Fujita, H. Palhares, A.P. da Silva, J.M. Tome, M.F. Borges, Clinical and laboratory parameters of gonadotropin-releasing hormone analog treatment effectiveness in children with precocious puberty. Clinics (Sao Paulo) 74, e1205 (2019)

19. K. Hari Kumar, "Make in India"-time for Indian protocols. Indian J. Endocrinol. Metab. 23(6), 591-592 (2019)

20. C.P. Houk, A.R. Kunselman, P.A. Lee, The diagnostic value of a brief GnRH analogue stimulation test in girls with central precocious puberty: a single 30-minute post-stimulation LH sample is adequate. J. Pediatr. Endocrinol. Metab. 21(12), 1113-1118 (2008)

21. G. Binder, R. Schweizer, G. Blumenstock, R. Braun, Inhibin B plus $\mathrm{LH}$ vs GnRH agonist test for distinguishing constitutional delay of growth and puberty from isolated hypogonadotropic hypogonadism in boys. Clin. Endocrinol. (Oxf) 82(1), 100-105 (2015)

22. P.M. Bossuyt, J.B. Reitsma, D.E. Bruns, C.A. Gatsonis, P.P. Glasziou, L. Irwig et al. STARD 2015: an updated list of essential items for reporting diagnostic accuracy studies. BMJ 351, h5527 (2015)

23. M. de Onis, A.W. Onyango, E. Borghi, A. Siyam, C. Nishida, J. Siekmann, Development of a WHO growth reference for schoolaged children and adolescents. Bull. World Health Organ. 85(9), 660-667 (2007)

24. WHO (2009). WHO AnthroPlus for personal computers: software for assessing growth of the world's children and adolescents (World Health Organization, Geneva, 2009), http://www.who.int/ growthref. Accessed Feb 18, 2021

25. W.A. Marshall, J.M. Tanner, Variations in pattern of pubertal changes in girls. Arch Dis Child 44(235), 291-303 (1969)

26. W.W. Greulich, S.I. Pyle, Radiographic atlas of skeletal development of the hand and wrist. 2nd edn. (Stanford University Press, Stanford, CA, 1959).

27. C. De Leonibus, M.L. Marcovecchio, F. Chiarelli, Update on statural growth and pubertal development in obese children. Pediatr. Rep. 4(4), e35 (2012)

28. S. Chung, Growth and puberty in obese children and implications of body composition. J. Obes. Metab. Syndr. 26(4), 243-250 (2017)

29. C. Bizzarri, G.L. Spadoni, G. Bottaro, G. Montanari, G. Giannone, M. Cappa et al. The response to gonadotropin releasing hormone $(\mathrm{GnRH})$ stimulation test does not predict the progression to true precocious puberty in girls with onset of premature thelarche in the first three years of life. J. Clin. Endocrinol. Metab. 99 (2), 433-439 (2014)

30. S. Schubert, A.H. Hvelplund, A. Handberg, S. Hagstroem, T.L. Leunbach, Elevated pre-injection basal luteinizing hormone concentrations are common in girls treated for central precocious puberty. J. Clin. Res. Pediatr. Endocrinol. 13(2), 204-211 (2021)

31. C.P. Houk, A.R. Kunselman, P.A. Lee, Adequacy of a single unstimulated luteinizing hormone level to diagnose central precocious puberty in girls. Pediatrics 123(6), e1059-e1063 (2009)

32. E.T. Vestergaard, M.E. Schjorring, K. Kamperis, K.K. Petersen, S. Rittig, A. Juul et al. The follicle-stimulating hormone (FSH) and luteinizing hormone (LH) response to a gonadotropinreleasing hormone analogue test in healthy prepubertal girls aged 10 months to 6 years. Eur. J. Endocrinol. 176(6), 747-753 (2017) 
33. H.K. Kim, S.J. Kee, J.Y. Seo, E.M. Yang, H.J. Chae, C.J. Kim, Gonadotropin-releasing hormone stimulation test for precocious puberty. Korean J. Lab. Med. 31(4), 244-249 (2011)

34. D.S. Lee, N.Y. Ryoo, S.H. Lee, S. Kim, J.H. Kim, Basal luteinizing hormone and follicular stimulating hormone: is it sufficient for the diagnosis of precocious puberty in girls? Ann. Pediatr. Endocrinol. Metab. 18(4), 196-201 (2013)
35. E.K. Choo, S.V. Rajkumar, Medication shortages during the COVID-19 crisis: what we must do. Mayo Clin Proc. 95(6), 1112-115 (2020)

36. H.A. Badreldin, B. Atallah, Global drug shortages due to COVID19: impact on patient care and mitigation strategies. Res. Social Adm. Pharm. 17(1),1946-1949 (2021). 